\title{
Paxilitaxel induces apoptosis accompanied by protective autophagy in osteosarcoma cells through hypoxia-inducible factor-1 $\alpha$ pathway
}

\author{
YUANQING GUO, CHUANGXIN HUANG, GUOWEI LI, TAO CHEN, JINXIANG LI and ZONGWEN HUANG \\ Department of Orthopedics, The Fifth Affiliated Hospital of Sun Yat-Sen University, \\ Zhuhai, Guangdong 519000, P.R. China
}

Received August 5, 2014; Accepted April 20, 2015

DOI: $10.3892 / \mathrm{mmr} .2015 .3860$

\begin{abstract}
Paxilitaxel, a drug used in cancer chemoprevention and treatment, has shown promising anti-cancer effects against a broad spectrum of tumors. However, the effect of paxilitaxel on osteoblasts has remained to be elucidated. The aim of the present study was to investigate the anti-tumor effect of paxilitaxel on human osteosarcoma cancer cells, the underlying molecular mechanism as well as drug resistance involved. The results showed that paxilitaxel not only induced apoptosis via the mitochondrial pathway but also induced autophagy, which partially inhibited cell apoptosis. The present study also demonstrated that paxilitaxel induced autophagy through the hypoxia-inducible factor (HIF)-1 $\alpha$ pathway. Moreover, paxilitaxel-induced apoptosis decreased following incubation with with the autophagy inducer rapamycin. By contrast, co-treatment with the HIF-1 $\alpha$ inhibitor YC-1 or autophagy inhibitor 3-methyladenine significantly blocked autophagy and augmented the anti-tumor effects of paxilitaxel. Therefore, the results of the present study suggested that the combination of paxilitaxel with an autophagy inhibitor or a HIF-1 $\alpha$ inhibitor may be an effective and potent strategy for improved chemotherapy of osteosarcoma in the future.
\end{abstract}

Correspondence to: Professor Zongwen Huang, Department of Orthopedics, The Fifth Affiliated Hospital of Sun Yat-Sen University, 52 Meihua East Road, Zhuhai, Guangdong 519000, P.R. China

E-mail: zongwen2014_3@163.com

Abbreviations: HIF-1, hypoxia-inducible factor 1; 3-MA, 3-methyladenine; RAPA, rapamycin; LC3I/II, microtubule-associated protein light chain 3-I/II; AIF, apoptosis-inducing factor; DMEM, Dulbecco's modified Eagle's medium; PI, propidium iodide; $\Delta \Psi \mathrm{m}$, mitochondrial membrane potential; YC-1, 3-(5'-hydroxymethyl-2'furyl)-1-benzyl indazole

Key words: paxilitaxel, autophagy, hypoxia-inducible factor-1 $\alpha$, osteosarcoma

\section{Introduction}

Osteosarcoma is the most common malignant tumor of bone, which mainly affects children and adolescents and accounts for $\sim 60 \%$ of malignant bone tumors diagnosed in the first two decades of life $(1,2)$. Current treatment of osteosarcoma consists of multiagent chemotherapy and surgical resection. However, further therapy with additional chemotherapy is palliative and too often toxic $(3,4)$. Thus, safe and more effective anti-cancer treatments are required for patients with osteosarcoma.

Paxilitaxel, which was isolated from the bark of the yew tree, inhibits the division of actively growing tumor cells and has become increasingly important in the treatment of a number of major cancers, including ovarian (5), pancreatic (6) and breast (7) cancer. However, the impact of paxilitaxel on osteoblasts has remained to be elucidated.

Autophagy is an evolutionarily conserved lysosomal degradation process by which cells recycle macromolecules and organelles (8). Studies have demonstrated that anti-cancer therapies (such as chemotherapy) induce autophagy in cancer cells, while the association between autophagy and therapeutic effects has remained controversial $(9,10)$. However, an increasing number of studies have reported that autophagy is elevated in certain tumors and contributes to poor outcome by promoting resistance to chemotherapy (11). It has remained elusive whether paxilitaxel is able to induce autophagy in osteosarcoma cells and, if so, what the significance of this response is.

Hypoxia-inducible factor 1 (HIF-1) is the most critical nuclear transcription factor under hypoxic conditions in normal cells and tumor cells. Studies have reported that HIF-1 $\alpha$ protein expression is upregulated in certain tumor types and contributes to poor disease outcome by promoting tumor progression, metastasis and resistance to chemotherapy $(12,13)$. Previous studies also showed that HIF and autophagy are closely linked $(14,15)$. Whether paxilitaxel is able to affect the expression of HIF-1 and autophagy, as well as the complex association between them, was the subject of the present study.

The present study investigated whether paxilitaxel induces apoptosis in human osteosarcoma cells. Furthermore, 
the ability of paxilitaxel to induce autophagy and HIF-1 $\alpha$ expression in osteosarcoma and its possible association with resistance were investigated.

\section{Materials and methods}

Cell cultures. The human osteosarcoma cell line MG-63 was obtained from the Cell Collection of the Chinese Academy of Sciences (Shanghai, China). The cells were cultured in Dulbecco's modified Eagle's medium (DMEM) (Gibco-BRL, Invitrogen Life Technologies, Carlsbad, CA, USA) with $10 \%$ fetal bovine serum (FBS; Gibco-BRL) at $37^{\circ} \mathrm{C}$ in a $5 \%$ $\mathrm{CO}_{2}$ incubator. The cells were routinely sub-cultured every 2-3 days. All experiments were performed on cells harvested at the mid-logarithmic growth phase. Briefly, the cells were treated with autophagy inhibitors: $50 \mu \mathrm{mol} / 13$-(5'-hydroxymethyl-2'-furyl)-1-benzyl indazole (YC-1) or $5 \mathrm{mM}$ 3-methyladenine (3-MA) (both Sigma-Aldrich, St. Louis, MO, USA), or with an autophagy inducer: $2 \mu \mathrm{M}$ rapamycin (RAPA; Sigma-Aldrich) in DMEM with 10\% FBS.

Reagents and antibodies. Paxilitaxel was purchased from Sigma-Aldrich. Mouse monoclonal anti-B-cell lymphoma 2-associated X protein (Bax; cat. no. sc-20067), mouse monoclonal anti-apoptosis-inducing factor (AIF; cat. no. sc-13116), and mouse monoclonal anti- $\beta$-actin (cat. no. sc-8432) antibodies were purchased from Santa Cruz Biotechnology, Inc. (Dallas, TX, USA). Rabbit monoclonal anti-caspase 3 (cat. no. 9664), rabbit polyclonal anti-caspase 9 (cat. no. 9502), rabbit monoclonal anti-Beclin1 (cat. no. 3495), rabbit monoclonal anti-microtubule-associated protein light chain 3 (LC3; cat. no. 12741) and rabbit monoclonal anti-HIF-1 $\alpha$ (cat. no. 14179) were purchased from Cell Signaling Technology (Danvers, MA, USA).

Analysis of apoptosis. Cellular apoptosis was determined using the Annexin V-fluorescein isothiocyanate (FITC) Apoptosis Detection kit I (Clontech Laboratories Inc., Takara Bio Inc., Mountain View, CA, USA). Brieflly, MG-63 cells were cultured at $4 \times 10^{6}$ cells $/ \mathrm{ml}$ and seeded in six-well plates. Cells were harvested by trypsinization (Sigma-Aldrich), then washed twice with cold phosphate-buffered saline (PBS) and centrifuged at $700 \times \mathrm{g} .1 \times 10^{5}-1 \times 10^{6}$ cells were re-suspended in $300 \mu \mathrm{l} 1 \mathrm{X}$ binding buffer (Clontech Laboratories Inc.), centrifuged again at $700 \mathrm{x}$ g for $5 \mathrm{~min}$ and then the supernatant was removed. Cells were re-suspended in $300 \mu \mathrm{l} 1 \mathrm{X}$ binding buffer and transferred to a sterile flow cytometry glass tube. $10 \mu \mathrm{l}$ Annexin V-FITC was added and cells were incubated in the dark for $30 \mathrm{~min}$ at room temperature. Cells were then incubated in the dark with $5 \mu \mathrm{l}$ propidium iodide (PI) and analyzed by flow cytometry (FACSCalibur; Becton Dickinson, Franklin Lakes, NJ, USA).

Hoechst 33342 staining. The cells were washed three times with PBS and fixed with 4\% paraformaldehyde (Sigma-Aldrich) for $60 \mathrm{~min}$ at $4^{\circ} \mathrm{C}$. After washing with PBS for three times, the cells were incubated with $0.2 \%$ Triton X-100 (Sigma-Aldrich) for $15 \mathrm{~min}$. Cells were then blocked with $5 \%$ bovine serum albumin (BSA; Sigma-Aldrich) for $60 \mathrm{~min}$ at room temperature and Hoechst 33342 (Sigma-Aldrich) was added to the cells for 20 min. After washing three times with PBS, cells were visualized under a fluorescence microscope (SZ51; Olympus Corporation, Tokyo, Japan).

Immunofluorescence staining. MG-63 cells were seeded in six-well plates for $24 \mathrm{~h}$. Cells were then washed once with ice-cold PBS and fixed with 4\% paraformaldehyde for $30 \mathrm{~min}$ at $4^{\circ} \mathrm{C}$. After washing with PBS three times, the cells were incubated with $1 \%$ Triton X-100 for $10 \mathrm{~min}$. The cells were blocked at non-specific antibody binding sites by incubating with $10 \%$ goat serum in PBS containing 0.3\% Triton X-100 and 0.5\% BSA for $30 \mathrm{~min}$ at room temperature, followed by incubation with a mouse antibody against Beclin1 (1:400 in PBS; Cell Signaling Technology) or LC3 (1:200 in PBS; Cell Signaling Technology) overnight. The samples were then incubated with either tetramethylrhodamine (TRITC)- or FITC-conjugated goat anti-rabbit immunoglobulin (Ig)G secondary antibodies (1:100 in PBS) for $0.5 \mathrm{~h}$ at room temperature. Cells initially incubated with anti-Beclin1 were incubated with the TRITC-conjugated secondary antibody, whereas those initially incubated with anti-LC3 were incubated with the FITC-conjugated secondary antibody. Hoechst 33342 was added to the cells for $15 \mathrm{~min}$. After washing three times with PBS, cells were visualized under a fluorescence microscope (SZ51; Olympus Corporation).

Assessment of the mitochondrial membrane potential $(\Delta \psi m)$. The $\Delta \psi \mathrm{m}$ was analyzed using the tetraethylbenzimidazolylcarbocyanine iodide (JC-1) assay (Beyotime, Nantong, China). JC-1 is a cationic dye that indicates the $\Delta \psi \mathrm{m}$ by reversibly shifting its fluorescence emission between green (JC-1 monomers indicating loss of $\Delta \psi \mathrm{m}$ ) and red (JC-1 aggregates indicating intact $\Delta \psi \mathrm{m}$ ). In brief, a staining mixture (300 nM JC-1) was prepared according to the manufacturer's instructions of the JC-1 kit. Cells were incubated in the staining mixture for $30 \mathrm{~min}$ at $37^{\circ} \mathrm{C}$. Thereafter, cells were washed twice with medium and re-suspended in fresh medium. $\Delta \psi \mathrm{m}$ was monitored using a fluorescence microscope.

Isolation of proteins from mitochondria and cytosol and western blot analysis. The preparation of proteins from the mitochondrial and cytosolic fractions and western blot were performed as described previously (16). The cells were washed twice in ice-cold PBS and re-suspended in five volumes of ice-cold extraction buffer $[20 \mathrm{mM}$ western blotting analysis (4-(2-hydroxyethyl)-1-piperazineethanesulfonic acid-KOH, $1.5 \mathrm{mM} \mathrm{MgCl}_{2}, 1 \mathrm{mM}$ EDTA, $1 \mathrm{mM}$ ethylene glycol tetraacetic acid, $1 \mathrm{mM}$ dithiothreitol and $0.1 \mathrm{mM}$ phenylmethanesulfonyl fluoride, pH 7.5; Sigma-Aldrich]. The re-suspended cells were homogenized with ten strokes of a Teflon homogenizer (2-16P; Sigma-Aldrich). The homogenates were centrifuged twice at $750 \mathrm{xg}$ for $10 \mathrm{~min}$ at $4^{\circ} \mathrm{C}$. The supernatants were centrifuged at $10,000 \mathrm{xg}$ for $15 \mathrm{~min}$ at $4^{\circ} \mathrm{C}$ to obtain the mitochondrial pellets. Cytosolic fractions were obtained after further centrifugation at $100,000 \mathrm{xg}$ for $1 \mathrm{~h}$ at $4^{\circ} \mathrm{C}$. The protein concentrations of the resulting supernatants and mitochondrial fractions were measured. The samples (10 $\mu \mathrm{g}$ protein) were separated by 10\% SDS-PAGE (Invitrogen Life Technologies). The proteins separated by SDS-PAGE were electrotransferred onto a Hybond-polyvinylidenefluoride (PVDF) membrane (Invitrogen Life Technologies). The individual SDS gels were distinguished 
A

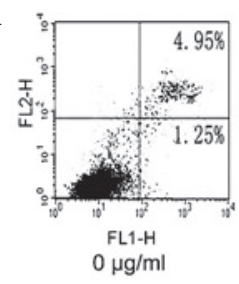

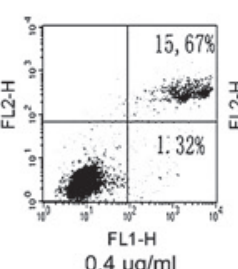

$0.4 \mu \mathrm{g} / \mathrm{ml}$

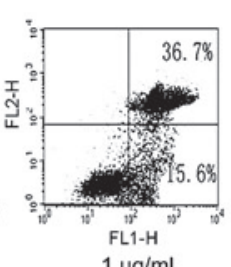

$1 \mu \mathrm{g} / \mathrm{ml}$
B

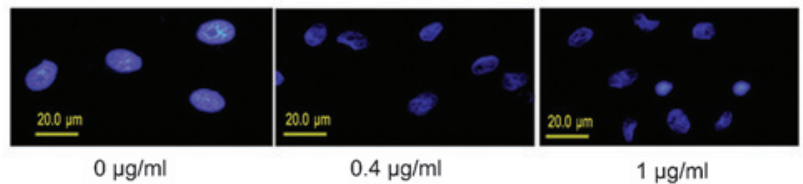

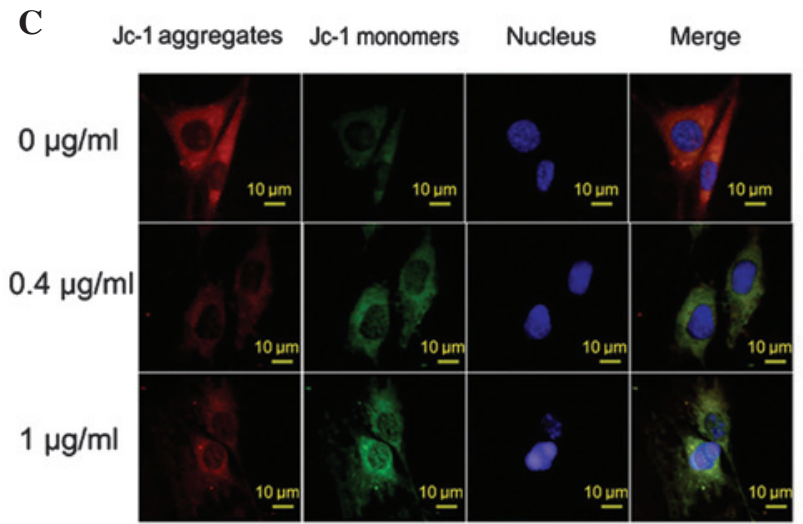

D
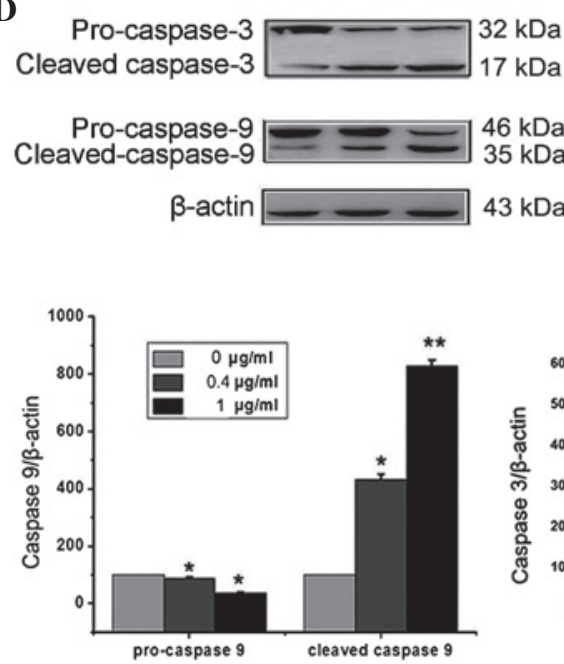

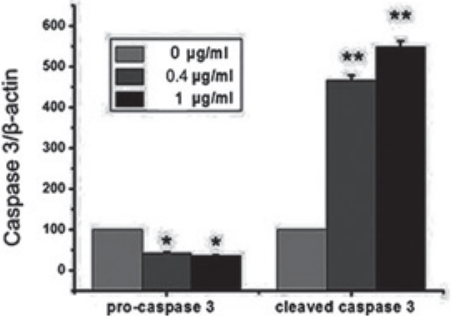

E (In mitochon

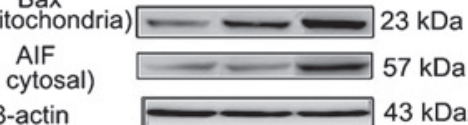

$\beta$-actin $43 \mathrm{kDa}$

Figure 1. Effects of paxilitaxel on the apoptosis of MG-63 cells. (A) Cells were treated with $0,0.4$ or $1 \mu \mathrm{g} / \mathrm{ml}$ paxilitaxel for $24 \mathrm{~h}$ and apoptosis was determined by flow cytometry followed by Annexin V-propidium iodide double staining. (B) Cells were treated as above, and the nuclei were stained with Hoechst 33342 and observed under a fluorescence microscope (scale bar, $20 \mu \mathrm{m}$ ). (C) Cells were treated as above and subjected to JC-1 staining for assessment of the mitochondrial membrane potential. JC-1 monomers (green fluorescence) indicate mitochondrial membrane potential loss, while JC-1 aggregates (red fluorescence) indicate a retained mitochondrial membrane potential (scale bar, $10 \mu \mathrm{m}$ ). (D) Cells were treated as described above, and levels of caspase 3 , caspase 9 were detected by western blot analysis. $\beta$-Actin was used as loading control. (E) Cells were treated as described above, and the expression of Bax (in the mitochondria) and AIF (in the cytosol) were detected by western blot analysis. $\beta$-Actin was used as loading control. Values are expressed as the mean \pm standard error ( $\mathrm{n}=10)$. $(* * \mathrm{P}<0.01 \mathrm{vs}$. control; * $\mathrm{P}<0.05$ vs. control). JC-1, tetraethylbenzimidazolylcarbocyanine iodide; Bax, B-cell lymphoma 2-associated X protein; AIF, apoptosis-inducing factor.

by placing the protein molecular weight marker (Invitrogen Life Technologies) in different but consistent positions. The PVDF membrane was then soaked in a blocking solution [5\% nonfat milk in TBST buffer $(20 \mathrm{mM}$ Tris-HCl, $\mathrm{pH} 7.5$, $0.5 \mathrm{M} \mathrm{NaCl}, 0.1 \%$ Tween 20; Sigma-Aldrich)] for $2 \mathrm{~h}$ at room temperature. The soaked PVDF membrane was then incubated in TBST containing primary antibodies overnight at $4^{\circ} \mathrm{C}$. The following primary antibodies were used: Anti-Bax, anti-AIF, and anti- $\beta$-actin (all Santa Cruz Biotechnology); Anti-caspase 3, anti-caspase 9, anti-LC3, anti-Beclin1 and anti-HIF-1 $\alpha$ (1:400 dilution; all Cell Signaling Technology). Following incubation, the blot was washed with TBST buffer three times for $5 \mathrm{~min}$ each and incubated at room temperature for $2 \mathrm{~h}$ in TBST containing horseradish peroxidase (HRP)-conjugated goat anti-mouse and goat anti-rabbit IgG (Santa Cruz Biotechnology, Inc.). The membrane was washed with TBST buffer three times for $10 \mathrm{~min}$ each. The membranes were incubated in enhanced chemiluminescence reagent (Pierce Biotechnology, Thermo Fisher Scientific, Waltham, MA, USA) for HRP (30 sec) and exposure to autoradiography film for visualization of the bands using a LAS-1000 system (Fujifilm, Tokyo, Japan). The relative amounts of various proteins were analyzed. The results were 
A

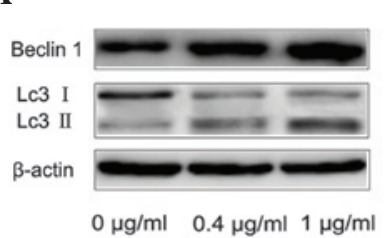

B

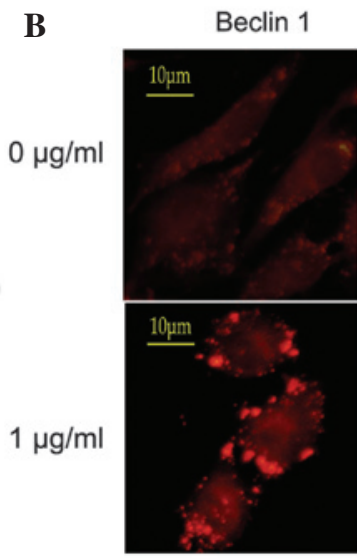

C

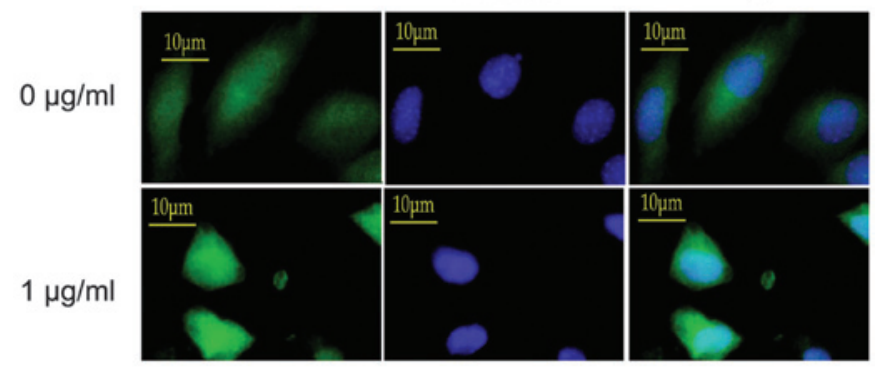

Figure 2. Effects of paxilitaxel on the autophagy of MG-63 cells. (A) Cells were treated with $0,0.4$ or $1 \mu \mathrm{g} / \mathrm{ml}$ paxilitaxel for $24 \mathrm{~h}$, and the expression of Beclin1 and Lc3II/I were detected by western blot analysis. $\beta$-Actin was used as a loading control. Values are expressed as the mean \pm standard error $(\mathrm{n}=10)$. $\left({ }^{* *} \mathrm{P}<0.01\right.$ vs. control). (B) MG-63 cells were treated with 0 or $1 \mu \mathrm{g} / \mathrm{ml}$ paxilitaxel for $24 \mathrm{~h}$, Beclin1 protein was visualized by immunofluorescent staining and fluorescence microscopy. (C) MG-63 cells were treated with 0 or $1 \mu \mathrm{g} / \mathrm{ml}$ paxilitaxel for $24 \mathrm{~h}$, and LC 3 protein was visualized by immunofluorescent staining and fluorescence microscopy. LC3, microtubule-associated protein light chain 3

quantified by Quantity One version 5.2.1 software (Bio-Rad Laboratories, Inc., Hercules, CA, USA).

Statistical analysis. Values are expressed as the mean \pm standard error of the mean $(n=10)$. Statistical analysis was performed using SPSS 18 (International Business Machines, Armonk, NY, USA). Data were analyzed using the one-way analysis of variance first. Individual comparisons were made using Tukey's multiple comparisons test. $\mathrm{P}<0.05$ was considered to indicate a statistically significant difference between values.

\section{Results}

Paxilitaxel induces apoptosis of MG-63 cells via a mitochondria-mediated pathway. First, the effects of paxilitaxel on human osteosarcoma cancer cells were tested and the mechanisms by which paxilitaxel induces MG-63 apoptosis at different concentrations were investigated. Cells were treated with $0,0.4$ and $1 \mu \mathrm{g} / \mathrm{ml}$ paxilitaxel for $24 \mathrm{~h}$ and the apoptotic rate was determined by Annexin V/PI double staining followed by flow cytometric analysis. The results showed a substantial increase in the apoptotic population among cells treated with paxilitaxel $(0.4$ or $1 \mu \mathrm{g} / \mathrm{ml})$ at $24 \mathrm{~h}$ (Fig. 1A). Fluorescence microscopy (Hoechst 33342 staining) demonstrated that the paxilitaxel-treated cells showed obvious nuclear damage in the form of chromatin condensation, which distinguished them from the cells in the control group (paxilitaxel $0 \mu \mathrm{g} / \mathrm{ml}$ ) (Fig. 1B). Following treatment with paxilitaxel, the $\Delta \psi \mathrm{m}$ in the cells was examined. Compared with control group, MG-63 cells in paxilitaxel groups exhibited green JC-1 fluorescence, indicating a reduction of the $\Delta \psi \mathrm{m}$ (Fig. 1C). As shown in Fig. 1D and E, the expression of Bax in the mitochondria was significantly increased in the paxilitaxel-treated groups compared to that in the control group $(\mathrm{P}<0.01)$, suggesting that the translocation of Bax into the mitochondria was involved in the induction of cell death by paxilitaxel. Mitochondria-mediated apoptosis comprises caspase-dependent and caspase-independent processes, where AIF is involved in the caspase-independent response. As shown in Fig. 1E, the expression of AIF in the cytosol was significantly increased in the paxilitaxel-treated groups compared to that in the control group $(\mathrm{P}<0.01)$. This result indicated that the release of AIF from the mitochondria to the cytosol was involved in cell death. Similarly, caspase- 3 and caspase- 9 were examined by western blot analysis. Levels of cleaved caspase- 3 and caspase- 9 in the paxilitaxel-treated groups were upregulated compared with those in the control group. These results indicated that paxilitaxel induced apoptosis in MG-63 cells was via a mitochondrial pathway involving the caspase-dependent pathway (caspase-3 and -9) as well as the caspase-independent pathway (AIF).

Paxilitaxel induces autophagy of MG-63 cells. Cells were treated with $0,0.4$ and $1 \mu \mathrm{g} / \mathrm{ml}$ paxilitaxel for $24 \mathrm{~h}$ and the occurrence of autophagy was determined. As shown in Fig. 2A, the expression levels of Beclin1 and LC3 II/I were significantly increased in the paxilitaxel-treated groups compared with those in the control group (paxilitaxel $0 \mu \mathrm{g} / \mathrm{ml} ; \mathrm{P}<0.01$ ), suggesting that paxilitaxel, in addition to triggering apoptosis, induced autophagy in MG-63 cells. Immunofluorescence microscopy revealed that in the control group, low levels of autophagy were sustained, while paxilitaxel markedly enhanced the levels of LC3 and Beclin1 (Fig. 2B and C). These findings indicated that paxilitaxel did not block autophagic flux, but induced the autophagic activity.

Paxilitaxel induces autophagy of MG-63 cells through the HIF-1 a pathway. It is well known that HIF and autophagy are closely linked $(13,14)$. Therefore, the present study investigated whether paxilitaxel treatment of MG-63 cells had any effect on the expression of HIF-1 $\alpha$. MG-63 cells were treated with 0.4 or $1 \mu \mathrm{g} / \mathrm{ml}$ paxilitaxel for $24 \mathrm{~h}$, and the expression levels of HIF-1 $\alpha$ were assessed by western blot analysis. As shown in Fig. 3A, paxilitaxel enhanced the levels of HIF-1 $\alpha$ compared to those in the control group. These 
A
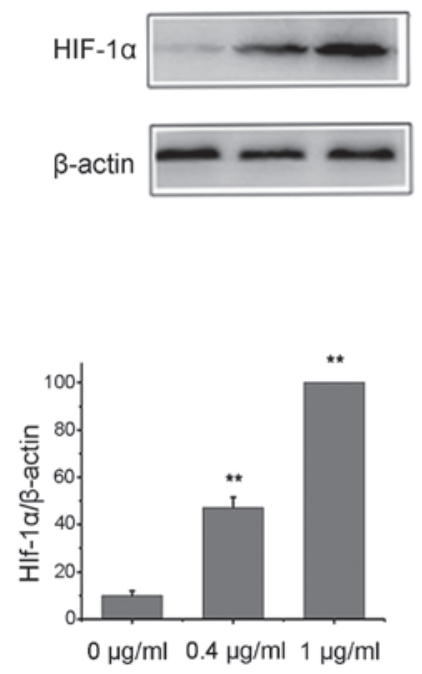

B

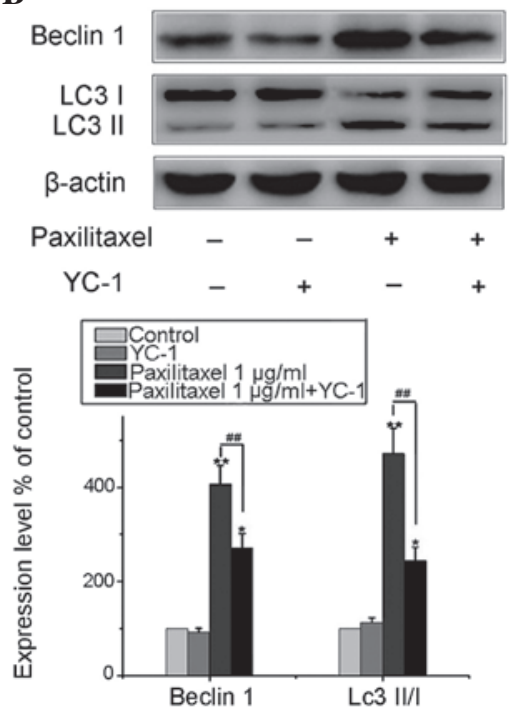

Figure 3. HIF-1 $\alpha$ induced by paxilitaxel contributes to the autophagy of MG-63 cells. (A) MG-63 cells were treated with $0,0.4$ and $1 \mu \mathrm{g} / \mathrm{ml}$ paxilitaxel for $24 \mathrm{~h}$, and the HIF-1 $\alpha$ protein was detected by western blot analysis. $\beta$-Actin was used as a loading control. Values are expressed as the mean \pm standard error ( $\mathrm{n}=10)$. $\left({ }^{* *} \mathrm{P}<0.01\right.$ vs. control). (B) MG-63 cells were exposed to $1 \mu \mathrm{g} / \mathrm{ml}$ paxilitaxel with or without HIF-1 $\alpha$ inhibitor YC-1 $(50 \mu \mathrm{mol} / 1)$ for $24 \mathrm{~h}$, and the expression of Beclin1 and LC3II/I were detected by western blot analysis. $\beta$-Actin was used as loading control. Values are expressed as the mean \pm standard error ( $\mathrm{n}=10$ ). ( $\mathrm{P}<0.05$ vs. control; ${ }^{* *} \mathrm{P}<0.01 \mathrm{vs}$. control; ${ }^{\# /} \mathrm{P}<0.01$ vs. $1 \mu \mathrm{g} / \mathrm{ml}$ paxilitaxel group). HIF, hypoxia-inducible factor; LC3, microtubule-associated protein light chain 3; YC-1, 3-(5'-hydroxymethyl-2'-furyl)-1-benzyl indazole.

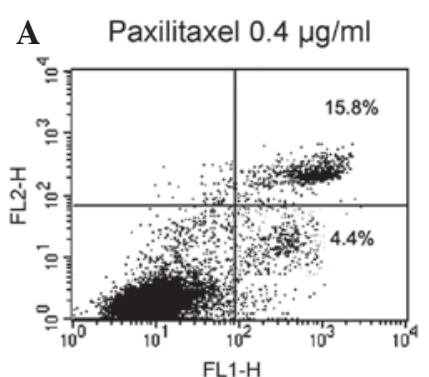

Paxilitaxel $0.4 \mu \mathrm{g} / \mathrm{ml}+3-\mathrm{MA}$

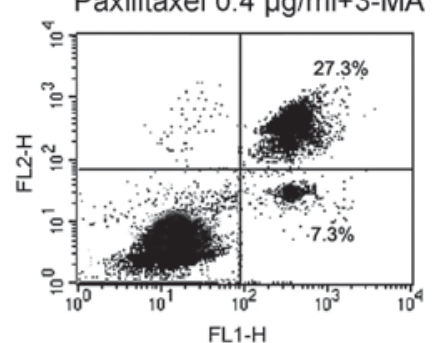

Paxilitaxel $0.4 \mu \mathrm{g} / \mathrm{ml}+\mathrm{YC}-1$

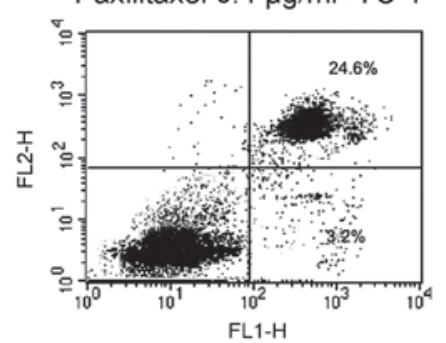

Paxilitaxel $0.4 \mu \mathrm{g} / \mathrm{ml}+\mathrm{RAPA}$

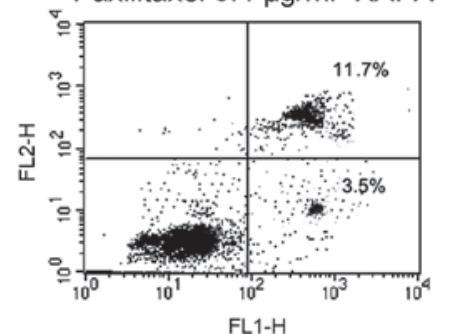

$\mathbf{B}$

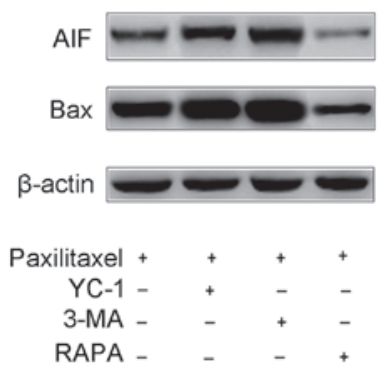

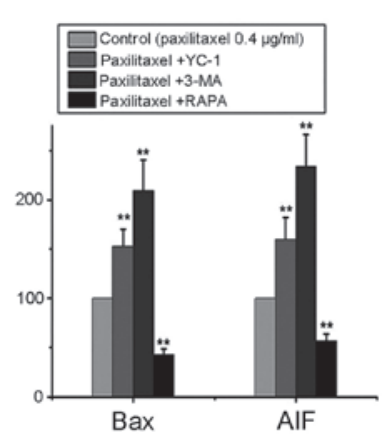

Figure 4. Autophagy is a protective mechanism in MG-63 cells. (A) Cells were treated with $0.4 \mu \mathrm{g} / \mathrm{ml}$ paxilitaxel with or without the autophagy inhibitors YC-1 $(50 \mu \mathrm{mol} / \mathrm{l})$ and 3-MA $(5 \mathrm{mM})$ or the autophagy inducer RAPA $(2 \mu \mathrm{M})$ for $24 \mathrm{~h}$, and apoptosis was determined by Annexin V-propidium iodide double staining and flow cytometry. (B) Cells were treated as above, and the expression of Bax (in the mitochondria) and AIF (in the cytosol) were detected by western blot analysis. $\beta$-Actin was used as a loading control. Values are expressed as the mean \pm standard error $(n=10)$. $\left({ }^{* *} \mathrm{P}<0.01 \mathrm{vs}\right.$. control). YC-1, 3-(5'-hydroxymethyl-2'-furyl)-1-benzyl indazole; Bax, B-cell lymphoma 2-associated X protein; AIF, apoptosis-inducing factor; 3-MA, 3-methyladenine; RAPA, rapamycin.

results indicated that paxilitaxel treatment not only resulted in apoptosis, but also in the induction of autophagy and the expression of HIF-1 $\alpha$. Following treatment with 0.4 and $1 \mu \mathrm{g} / \mathrm{ml}$ paxilitaxel, autophagy-associated protein as well as and HIF-1 $\alpha$ protein levels were increased in a dose-dependent manner (Figs. 2A and 3A). However, it appeared unlikely that paxilitaxel induced autophagy by upregulating the expression of HIF-1 $\alpha$ alone. Therefore, MG-63 cells were exposed to $1 \mu \mathrm{g} / \mathrm{ml}$ paxilitaxel in the presence of the HIF-1 $\alpha$ inhibitor
YC-1 [50 $\mu \mathrm{mol} / 1$ in accordance with reference (17)] for $24 \mathrm{~h}$ and the expression of Beclin1 and LC3II/I was detected by western blot analysis. The results indicated that paxilitaxel-mediated upregulation of autophagy-associated protein expression was attenuated, but not fully abolished by HIF-1 $\alpha$ inhibitor YC-1 (Fig. 3B). Therefore, these results indicated that HIF-1 $\alpha$ generation by paxilitaxel has an important role in autophagy induction; however, there are likely to be additional signaling proteins via which autophagy is induced by paxilitaxel. 
Autophagy induced by paxilitaxel protects $M G-63$ cells from apoptosis. To investigate the effect of autophagy on the apoptosis of MG-63 cells, 3-MA, a potent pharmacological inhibitor of autophagy, was used to suppress the autophagy induced by paxilitaxel. The results demonstrated that pre-treatment with 3-MA [5 mM according to reference (18)] was able to block autophagy in MG-63 cells without significant cytotoxicity. 3-MA itself scarcely induced cell apoptosis and cell death, but significantly increased apoptosis at $24 \mathrm{~h}$ after paxilitaxel exposure (paxilitaxel group, 20.2\%; paxilitaxel plus 3-MA, 34.6\%). In addition, in the group of combined treatment of $0.4 \mu \mathrm{g} / \mathrm{ml}$ paxilitaxel and $50 \mu \mathrm{mol} / 1 \mathrm{YC}-1$ for $24 \mathrm{~h}$, the apoptotic rate was higher than that in the group treated with paxilitaxel only (paxilitaxel group, 20.2\%; paxilitaxel plus YC-1, 27.8\%) (Fig. 4A). These results suggested that suppression of autophagy by 3-MA or YC-1 increased paxilitaxel-induced injury in MG-63 cells. By contrast, paxilitaxel-induced apoptosis decreased following co-treatment with autophagy inducer RAPA [ $2 \mu \mathrm{M}$ according to reference (19)] compared to that of cells treated with paxilitaxel alone (Fig. 4A). Treatment of MG-63 cells with RAPA or 3-MA alone did not affect cell viability (data not shown). The results were further confirmed by western blot analysis. The upregulation of the expression of apoptotic proteins AIF and Bax was more marked when cells were co-treated with 3-MA, while it was attenuated by co-treatment with RAPA (Fig. 4B). These results indicated that autophagy induced by paxilitaxel had a protective effect on MG-63 cells, and blockage of autophagy enhanced the anti-tumor effect of paxilitaxel.

\section{Discussion}

Paxilitaxel is an active component of the herbal medicine Curcuma wenyujin with reported anti-tumor activity and has been approved for the treatment of malignant effusion and certain types of solid tumor in China $(20,21)$. However, to the best of our knowledge, the effects of paxilitaxel on osteosarcoma have not been documented. In the present study, paxilitaxel was shown to inhibit the proliferation and induce apoptosis of human osteosarcoma cells. Mitochondria has an important role in the regulation of cell death. Mitochondrial dysfunction is considered an early event in apoptosis and this process accompanied with a conspicuous reduction of the mitochondrial membrane potential $(22,23)$. The present study found that paxilitaxel-treated cells exhibited green JC-1 fluorescence, indicating a reduction of the $\Delta \psi \mathrm{m}$. Paxilitaxel treatment led to a marked upreguration of cleaved-caspase 3, cleaved-caspase 9, Bax (in the mitochondria) and AIF (in the cytosol), while significantly downregulating the levels of pro-caspase 3 and pro-caspase 9. These results suggested that paxilitaxel is capable of inducing mitochondria-mediated apoptosis involving the caspase-dependent (via caspase-3 and -9) as well as the caspase-independent pathway (via AIF).

Autophagy, an evolutionarily conserved lysosome-dependent cellular catabolic degradation process, is characterized by the formation of autophagosomes (24). Autophagy has a housekeeping role in clearing damaged organelles, including mitochondria and peroxisomes, as well as eliminating intracellular pathogens. Thus, autophagy is generally regarded as a survival mechanism $(25,26)$. Autophagy and apoptosis are closely associated. Apoptosis is often accompanied by the occurrence of autophagy $(27,28)$. It was found that paxilitaxel not only induced apoptosis but also induced autophagy in MG-63 cells. The autophagy proteins Beclin1 and LC3 were upregulated by paxilitaxel. Moreover, in accordance with the results of previous studies $(29,30)$, the present study reported that paxilitaxel activated autophagy by modulation of HIF-1 $\alpha$ signaling. Paxilitaxel induced autophagy as well as HIF-1 $\alpha$ expression in MG-63 cells. This autophagic induction by paxilitaxel was partly mediated through the activation of HIF-1 $\alpha$, as inhibition of HIF-1 $\alpha$ expression by YC-1 reduced autophagy.

Autophagy has an important role in mediating the effects of drugs in cells. Autophagy and HIF-1 $\alpha$ are often associated with resitance to chemotherapy (31-33). The results of the present study suggested that autophagy is a pro-survival mechanism of MG-63 cells following paxilitaxel treatment and facilitates the development of acquired paxilitaxel resistance. Paxilitaxel-induced apoptosis of MG-63 cells was markedly decreased by autophagy. In addition, co-treatment with clinically applicable inhibitors of autophagy or HIF-1 $\alpha$ may be one of the important strategies for human osteosarcoma therapy. Suppression of autophagy by 3-MA or YC-1 was able to increase paxilitaxel-induced apoptosis in MG-63 cells. By contrast, paxilitaxel-induced apoptosis was decreased following co-treatment with the autophagy inducer RAPA. However, the molecular mechanisms of HIF-1 $\alpha$-mediated activation of autophagy and paxilitaxel resistance, as well as the association between autophagy, apoptosis and other factors of paxilitaxel-resistance require further study. At present, the precise underlying mechanism of autophagy mediated by anti-apoptotic proteins remains elusive and is under investigation in our laboratory.

\section{References}

1. Markiewicz K, Zeman K, Kozar A and Gołebiowska-Wawrzyniak M: Evaluation of selected cytokines in children and adolescents with osteosarcoma at diagnosis-preliminary report. Med Wieku Rozwoj 15: 25-31, 2011 (In Polish).

2. Daw NC, Neel MD, Rao BN, Billups CA, Wu J, Jenkins JJ, Quintana J, Luchtman-Jones L, Villarroel M and Santana VM: Frontline treatment of localized osteosarcoma without methotrexate: results of the St. Jude Children's Research Hospital OS99 trial. Cancer 117: 2770-2778, 2011.

3. DeRegis CJ, Moore AS, Rand WM and Berg J: Cisplatin and doxorubicin toxicosis in dogs with osteosarcoma. J Vet Intern Med 17: 668-673, 2003.

4. Moore-Maxwell CA, Datto MB and Hulette CM: Chemotherapy-induced toxic leukoencephalopathy causes a wide range of symptoms: a series of four autopsies. Mod Pathol 17: 241-247, 2004.

5. Yoneyama K, Konishi H, Yahata T, Fujita K, Aoki Y, Doi D, Matsushima T, Kodama S, Honma S, Kato H, Nakayama H, et al: A Phase II study of paclitaxel and carboplatin with a biweekly schedule in patients with epithelial ovarian cancer: Gynecologic cancer network trial. J Nippon Med Sch 81: 28-34, 2014.

6. Von Hoff DD, Goldstein D and Renschler MF: Albumin-bound paclitaxel plus gemcitabine in pancreatic cancer. $\mathrm{N}$ Engl $\mathrm{J}$ Med 370: 479-480, 2014.

7. Dank M, Budi L, Piko B, Mangel L, Erfan J, Cseh J, Ruzsa A and Landherr L: First-line bevacizumab-paclitaxel in 220 patients with metastatic breast cancer: Results from the AVAREG study. Anticancer Res 34: 1275-1280, 2014

8. Orvedahl A, Sumpter R Jr, Xiao G, Ng A, Zou Z, Tang Y, Narimatsu M, Gilpin C, Sun Q, Roth M, Forst CV, et al: Image-based genome-wide siRNA screen identifies selective autophagy factors. Nature 480: 113-117, 2011. 
9. Maycotte P, Aryal S, Cummings CT, Thorburn J, Morgan MJ and Thorburn A: Chloroquine sensitizes breast cancer cells to chemotherapy independent of autophagy. Autophagy 8: 200-212, 2012.

10. Nakamura O, Hitora T, Akisue T, Kawamoto T, Yamagami Y and Yamamoto T: Inhibition of induced autophagy increases apoptosis of Nara-H cells. Int J Oncol 39: 1545-1452, 2011.

11. Mani J, Vallo S, Rakel S, Antonietti P, Gessler F, Blaheta R, Bartsch G, Michaelis M, Cinatl J, Haferkamp A and Kögel D: Chemoresistance is associated with increased cytoprotective autophagy and diminished apoptosis in bladder cancer cells treated with BH3 mimetic (-)-Gossypol (AT-101). BMC Cancer 15: 224, 2015.

12. Monti E and Gariboldi MB: HIF-1 as a target for cancer chemotherapy, chemosensitization and chemoprevention. Curr Mol Pharmacol 4: 62-77, 2011.

13. Generali D, Buffa FM, Berruti A, Brizzi MP, Campo L, Bonardi S, Bersiga A, Allevi G, Milani M, Aguggini S, Papotti M, et al: Phosphorylated ERalpha, HIF-1alpha and MAPK signaling as predictors of primary endocrine treatment response and resistance in patients with breast cancer. J Clin Oncol 27: 227-234, 2009

14. Zhao Y, Chen G, Zhang W, Xu N, Zhu JY, Jia J, Sun ZJ, Wang YN and Zhao YF: Autophagy regulates hypoxia-induced osteoclastogenesis through the HIF-1 $\alpha /$ BNIP3 signaling pathway. Cell Physiol 227: 639-648, 2012.

15. Zhang H, Bosch-Marce M, Shimoda LA, Tan YS, Baek JH Wesley JB, Gonzalez FJ and Semenza GL: Mitochondrial autophagy is an HIF-1-dependent adaptive metabolic response to hypoxia. Biol Chem 283: 10892-10903, 2008.

16. Wessel D and Flügge UI: A method for the quantitative recovery of protein in dilute solution in the presence of detergents and lipids. Anal Biochem 138: 141-143, 1984.

17. Adesida AB, Grady LM, Khan WS, Millward-Sadler SJ, Salter DM and Hardingham TE: Human meniscus cells express hypoxia inducible factor- $1 \alpha$ and increased SOX9 in response to low oxygen tension in cell aggregate culture. Arthritis Res Ther 9: R69, 2007.

18. Zeng Y, Yang X, Wang J, Fan J, Kong Q and Yu X: Aristolochic acid I induced autophagy extenuates cell apoptosis via ERK $1 / 2$ pathway in renal tubular epithelial cells. PLoS One 7: e30312, 2012.

19. Amarnath S, Flomerfelt FA, Costanzo CM, Foley JE, Mariotti J, Konecki DM, Gangopadhyay A, Eckhaus M, Wong S, Levine BL, June $\mathrm{CH}$ and Fowler DH: Rapamycin generates anti-apoptotic human Th1/Tc1 cells via autophagy for induction of xenogeneic GVHD. Autophagy 6: 523-541, 2010.

20. Yao YQ, Ding X, Jia YC, Huang CX, Wang YZ and Xu YH: Anti-tumor effect of betapaxilitaxel in glioblastoma cells depends on p38 MAPK activation. Cancer Lett 264: 127-134, 2008.

21. Wang G, Li X, Huang F, Zhao J, Ding H, Cunningham C, Coad JE, Flynn DC, Reed E and Li QQ: Antitumor effect of betapaxilitaxel in non-small-cell lung cancer cells is mediated via induction of cell cycle arrest and apoptotic cell death. Cell Mol Life Sci 62: 881-893, 2005.
22. Guo B, Yang M, Liang D, Yang L, Cao J and Zhang L: Cell apoptosis induced by zinc deficiency in osteoblastic MC3T3-E1 cells via a mitochondrial-mediated pathway. Mol Cell Biochem 361: 209-216, 2012.

23. Rasul A, Yu B, Yang LF, Ali M, Khan M, Ma T and Yang H: Induction of mitochondria-mediated apoptosis in human gastric adenocarcinoma SGC-7901 cells by kuraridin and Nor-kurarinone isolated from Sophora flavescens. Asian Pac J Cancer Prev 12: 2499-2504, 2011.

24. Granell S and Baldini G: Inclusion bodies and autophagosomes: are ER-derived protective organelles different than classical autophagosomes? Autophagy 4: 375-377, 2008.

25. Deretic V, Delgado M, Vergne I, Master S, De Haro S, Ponpuak M and Singh S: Autophagy in immunity against mycobacterium tuberculosis: a model system to dissect immunological roles of autophagy. Curr Top Microbiol Immunol 335: 169-188, 2009.

26. Hofius D, Munch D, Bressendorff S, Mundy J and Petersen M: Role of autophagy in disease resistance and hypersensitive response-associated cell death. Cell Death Differ 18: 1257-1262, 2011.

27. Zhang T, Li Y, Park KA, Byun HS, Won M, Jeon J, Lee Y, Seok JH, Choi SW, Lee SH, Man Kim J, et al: Cucurbitacin induces autophagy through mitochondrial ROS production which counteracts to limit caspase-dependent apoptosis. Autophagy 8: 559-576, 2012.

28. Ait-Mohamed O, Battisti V, Joliot V, Fritsch L, Pontis J Medjkane S, Redeuilh C, Lamouri A, Fahy C, Rholam M, Atmani D and Ait-Si-Ali S: Acetonic extract of Buxus sempervirens induces cell cycle arrest, apoptosis and autophagy in breast cancer cells. PLoS One 6: e24537, 2011.

29. Lu HH, Kao SY, Liu TY, Liu ST, Huang WP, Chang KW and Lin SC: Areca nut extract induced oxidative stress and upregulated hypoxia inducing factor leading to autophagy in oral cancer cells. Autophagy 6: 725-737, 2010.

30. Bellot G, Garcia-Medina R, Gounon P, Chiche J, Roux D, Pouysségur J and Mazure NM: Hypoxia-induced autophagy is mediated through hypoxia-inducible factor induction of BNIP3 and BNIP3L via their BH3 domains. Mol Cell Biol 29: 2570-2581, 2009

31. Liu L, Yang M, Kang R, Wang Z, Zhao Y, Yu Y, Xie M, Yin X, Livesey KM, Loze MT, Tang D and Cao L: DAMP-mediated autophagy contributes to drug resistance. Autophagy 7: 112-124, 2011.

32. Carew JS, Nawrocki ST, Kahue CN, Zhang H, Yang C, Chung L, Houghton JA, Huang P, Giles FJ and Cleveland JL: Targeting autophagy augments the anticancer activity of the histone deacetylase inhibitor SAHA to overcome Bcr-Abl-mediated drug resistance. Blood 110: 313-322, 2007.

33. Doublier S, Belisario DC, Polimeni M, Annaratone L, Riganti C, Allia E, Ghigo D, Bosia A and Sapino A: HIF-1 activation induces doxorubicin resistance in MCF7 3-D spheroids via P-glycoprotein expression: a potential model of the chemo-resistance of invasive micropapillary carcinoma of the breast. BMC Cancer 12: 4, 2012. 